\title{
Degradable biocomposite of nano calcium- deficient hydroxyapatite-multi(amino acid) copolymer
}

This article was published in the following Dove Press journal:

International Journal of Nanomedicine

7 March 2012

Number of times this article has been viewed

\author{
Hong $\mathrm{Li}^{\prime}$ \\ Min Gong' \\ Aiping Yang' \\ Jian $\mathrm{Ma}^{2}$ \\ Xiangde $\mathrm{Li}^{3}$ \\ Yonggang Yan' \\ 'School of Physical Science and \\ Technology, Sichuan University, \\ Chengdu People's Republic of \\ China; ${ }^{2}$ Hospital of Stomatology, \\ Tongji University, Shanghai, People's \\ Republic of China; ${ }^{3}$ Key Laboratory \\ for Ultrafine Materials of Ministry \\ of Education, East China University \\ of Science and Technology, Shanghai, \\ People's Republic of China
}

Background and methods: A nano calcium-deficient hydroxyapatite (n-CDHA)-multi(amino acid) copolymer (MAC) composite bone substitute biomaterial was prepared using an in situ polymerization method. The composition, structure, and compressive strength of the composite was characterized, and the in vitro degradability in phosphate-buffered solution and preliminary cell responses to the composite were investigated.

Results: The composite comprised n-CDHA and an amide linkage copolymer. The compressive strength of the composite was in the range of 88-129 MPa, varying with the amount of n-CDHA in the MAC (ranging from $10 \mathrm{wt} \%$ to $50 \mathrm{wt} \%$ ). Weight loss from the composite increased (from $32.2 \mathrm{wt} \%$ to $44.3 \mathrm{wt} \%$ ) with increasing $\mathrm{n}-\mathrm{CDHA}$ content (from $10 \mathrm{wt} \%$ to $40 \mathrm{wt} \%$ ) in the MAC after the composite was soaked in phosphate-buffered solution for 12 weeks. The $\mathrm{pH}$ of the soaking medium varied from 6.9 to 7.5 . MG-63 cells with an osteogenic phenotype were well adhered and spread on the composite surface. Viability and differentiation increased with time, indicating that the composite had no negative effects on MG-63 cells.

Conclusion: The n-CDHA-MAC composite had good cytocompatibility and has potential to be used as a bone substitute.

Keywords: calcium deficient hydroxyapatite, multi(amino acid) copolymer, biocomposite, degradability, cytocompatibility

\section{Introduction}

For bone tissue substitute and repair, it is known that a biocomposite containing a bioceramic such as hydroxyapatite and a polymer normally possesses both bioactivity (ceramic) and ductility (polymer). ${ }^{1-3}$ Hence, in designing a new inorganic/organic biocomposite, the choice of an inorganic component and a polymer are key to formulating a composite with favorable bioperformance. Nano hydroxyapatite biomaterials have being extensively developed for biomedical applications in recent decades because they have good biocompatibility and bioactivity, and can bond with host bone directly. ${ }^{3-5}$ However, nano hydroxyapatite, with an atomic molar $\mathrm{Ca} / \mathrm{P}$ ratio of 1.67 , is very stable and hence shows poor degradability in vivo, which greatly limits its clinical application. ${ }^{6}$ Recently, an increasing number of studies have been focusing on the development of nano calcium-deficient hydroxyapatite (n-CDHA, $\left.\mathrm{Ca}_{10-\mathrm{X}}\left(\mathrm{HPO}_{4}\right)_{\mathrm{X}}\left(\mathrm{PO}_{4}\right)_{6-\mathrm{X}}(\mathrm{OH})_{2-\mathrm{X}}, 0 \leq \mathrm{x}<1\right) .{ }^{6-10}$ Compared with nano hydroxyapatite, $\mathrm{CDHA}$ has higher solubility (ie, degradability) at a lower $\mathrm{Ca} / \mathrm{P}$ ratio (1.5-1.67), as well as being more similar in composition and crystal structure to the mineral of natural bone..$^{7-9}$ Thus, n-CDHA is a better candidate as the inorganic phase of a degradable biocomposite.
Correspondence: Aiping Yang School of Physical Science and Technology, Sichuan University, Chengdu 610064, People's Republic of China Tel +862885127592 Fax +862885127592 Email hlisoft@yahoo.com.cn 
Degradable polymers have been extensively investigated as biomaterials due to their favorable biocompatibility and degradation properties, their absorbability in vivo, and ability to disappear eventually with time. ${ }^{11-13}$ a-L-amino acids and glycine are the basic units of proteins. ${ }^{14}$ Poly(amino acid)s and copolymers based on such amino acids are favorable for use in tissue engineering, drug release, and regenerative medicine. ${ }^{11}$ However, these polymers generally have poor thermal stability, and poor processing and mechanical properties, so have limited biomedical applications. $\omega$-amino acid has a structure similar to that of a L-amino acid and its polymer, polyamide, which has excellent mechanical and processing properties, as well as good biocompatibility. However, polyamide is not degradable because of its high crystallinity and the strong actions of the hydrogen bonds existing in its macromolecular structure. Therefore, it is expected that addition of a-L-amino acids to poly ( $\omega$-amino acid)s could change the polymeric molecular structure and improve degradability. Studies have reported the synthesis and properties of copolymers consisting of 6-aminocaproic acid and a-L-proline, 6-aminocaproic acid and L-leucine. However, these polymers show a low rate of degradability, with only $6-10 \mathrm{wt} \%$ being lost after 4 weeks of soaking. ${ }^{14,15}$

Recently, a multi(amino acid) copolymer (MAC) consisting of 6-aminocaproic acid and five amino acids was developed in our laboratory. This copolymer could be degraded in HCL-Tris solution with weight loss of about $30 \mathrm{wt} \%$ after 12 weeks of soaking. ${ }^{16}$ In particular, our results show that during the degradation period, this copolymer had no significant effect on the $\mathrm{pH}$ of the ambient environment and maintained a complete structure and adequate mechanical strength compared with other degradation polymers, such as polylactic acid and it copolymers. Cell culture experiments and in vivo implantation results show that the copolymer also had good biocompatibility. Thus, the composite of the copolymer with n-CDHA is a new biomaterial with potential medical applications. The purpose of this study was to prepare a novel composite composed of n-CDHA and MAC. In addition, the in vitro degradability of the n-CDHA-MAC composite in phosphate-buffered solution and preliminary cell responses to the composite were investigated.

\section{Materials and methods}

\section{Synthesis of $n-C D H A-M A C$ composite}

n-CDHA was prepared as already described in the published literature. ${ }^{17}$ The n-CDHA-MAC composite was synthesized using an in situ polymerization method. Six grams of alanine, $7 \mathrm{~g}$ of phenylalanine, $1 \mathrm{~g}$ of glycine, $105 \mathrm{~g}$ of 6-aminocaproic acid, $6 \mathrm{~g}$ of proline, $2 \mathrm{~g}$ of lysine, and n-CDHA slurry (5 g n-CDHA/100 mL water) were added to a three-necked flask with continuous stirring. The reaction system was heated using an oil bath. The mixture was heated to $200^{\circ} \mathrm{C}$ for about 2 hours until the water was fully evaporated, and the mixture was melted. The system was then kept at $21^{\circ} \mathrm{C}$ for 2 hours and then at $220^{\circ} \mathrm{C}$ for one hour. After cooling to room temperature, the target composites were obtained. The reaction system was protected by a continuous flow of nitrogen gas to avoid undesirable oxidation reactions. The MAC was prepared by the same procedure without addition of n-CDHA, and used as a control. Composites with $10 \mathrm{wt} \%, 20 \mathrm{wt} \%, 30 \mathrm{wt} \%, 40 \mathrm{wt} \%$, and $50 \mathrm{wt} \% \mathrm{n}-\mathrm{CDHA}$ were prepared and named as 10CDHAMAC, 20CDHA-MAC, 30CDHA-MAC, 40CDHA-MAC, and 50CDHA-MAC, respectively.

\section{Characterization of $n-C D H A-M A C$ composite}

The morphology of n-CDHA was observed under a transmission electron microscope (JEM-100CX; JEOL, Tokyo, Japan). The atomic molar ratio of $\mathrm{Ca} / \mathrm{P}$ was analyzed by inductively coupled plasma atomic emission spectroscopy (IRIS 1000; Thermo Elemental, Franklin, MA). The composition and structure of the 30CDHA-MAC composite were characterized by Fourier transform infrared spectroscopy (170SX FT-IR Spectrometer; Nicolet, Madison, WI) and X-ray diffraction (X'Pert pro-MPD; Philips, Eindhoven, The Netherlands). To observe the n-CDHA distribution in MAC matrices, the 30CDHA-MAC composite was fractured in liquid nitrogen, and a cross-sectional specimen was observed under a scanning electron microscope (Hitachi $\mathrm{S}-450)$. In addition, the effects of the amount of $\mathrm{n}$-CDHA on the compressive strength of the composite were assessed in the composite samples $(\Phi 10 \times 12 \mathrm{~mm})$ containing different amounts of n-CDHA (0 wt $\%, 10 \mathrm{wt} \%, 20 \mathrm{wt} \%, 30 \mathrm{wt} \%$, $40 \mathrm{wt} \%$, and $50 \mathrm{wt} \%$ ) using a mechanical testing machine (REGER 30-50; Shenzhen Reger Co, Ltd, Shenzhen, China) with $50 \mathrm{kN}$ load cells. The cross-head speed was $5 \mathrm{~mm} / \mathrm{minute}$, and the load was applied until the specimens were compressed to about $20 \%$ of their original height. Five replicates were carried out for each group, and the results are expressed as the mean \pm standard deviation.

\section{In vitro degradability}

The in vitro degradability of the composite was performed by soaking the samples $(\Phi 12 \times 2 \mathrm{~mm})$ in phosphate-buffered solution $(\mathrm{pH}=7.4)$ for 12 weeks. After being washed with 
purified water and dried, the samples were weighed [the initial weight $\left.\left(\mathrm{W}_{0}\right)\right]$, and then soaked in phosphate-buffered solution with a solid/liquid mass ratio of $1 \mathrm{~g} / 100 \mathrm{~mL}$ in PE tubes. The tubes were capped and placed in a shaking water bath $\left(37^{\circ} \mathrm{C}\right.$ and $\left.72 \mathrm{rpm}\right)$, and the phosphate-buffered solution was replenished every week. The samples were washed and dried at weeks 1, 2, 4, 8, and 12, and the residual weight was calculated $\left(\mathrm{W}_{\mathrm{t}}\right)$. The weight loss ratio was calculated according to the following equation:

$$
\text { weight loss }(\%)=100\left(\mathrm{~W}_{0}-\mathrm{W}_{\mathrm{t}}\right) / \mathrm{W}_{0}
$$

The $\mathrm{pH}$ of the the phosphate-buffered solution was measured before being refreshed using an electrolyte-type $\mathrm{pH}$ meter (PS-25, Leici Instrument Factory, Shanghai, China).

\section{Cytocompatibility}

MG-63 osteoblast-like cells were cultured in Dulbecco's Modified Eagle Medium supplemented with 10\% fetal bovine serum plus $100 \mathrm{U} / \mathrm{mL}$ penicillin and $100 \mu \mathrm{g} / \mathrm{mL}$ streptomycin sulfate at $37^{\circ} \mathrm{C}$ in a humidified $5 \% \mathrm{CO}_{2}$ atmosphere. The cells were incubated in $25 \mathrm{~cm}^{2}$ flasks to reach $80 \%$ confluence and were then detached for further experiments. The 30CDHA-MAC composite and MAC samples with a size of $\Phi 12 \times 2 \mathrm{~mm}$ were used for all the cell culture experiments, and a tissue culture plate was used as the control. The samples were sonicated in ethanol and sterilized using ethylene oxide gas.

\section{Cell adhesion}

To investigate cell adhesion on the samples, MG-63 cells at a density of $2 \times 10^{4}$ cells/well were seeded onto samples located in 24-well tissue culture plates. The cells were allowed to adhere for one hour, after which each well was gently flooded with $1 \mathrm{~mL}$ medium. The cell and samples were cultured at $37^{\circ} \mathrm{C}$ and $\mathrm{CO}_{2} 5 \%$ in a humidified atmosphere for 4 hours, and the unattached cells were then removed by washing with phosphate-buffered solution three times. After the cells attached to the samples were digested by trypsin, the adherent cells were counted using a hemacytometer, and cell attachment efficiency was determined by counting the number of cells remaining in the wells. Five replicates were carried out for each sample, and the results were expressed as the mean \pm standard deviation.

\section{Cell viability}

The viability of MG-63 cells on the samples was determined using the MTT (3-\{4,5-dimethylthiazol-2yl\}-2,5-diphenyl$2 \mathrm{H}$-tetrazolium-bromide) assay. MTT measures changes in absorbance at a specific wavelength and is widely used for measuring cytotoxicity and cell viability. The production of purple formazan in osteoblast cultures with or without the samples was measured after days 1, 3, 5, and 7 of incubation in 24-well culture plates. For this purpose, $100 \mu \mathrm{L}$ of MTT (MajorBiochem, Shanghai, China) solution $(5 \mathrm{mg} / \mathrm{mL})$ was added to each well (containing either cells alone or pellets with adherent cells removed from the original culturing well) and the cells were incubated for 4 hours. Subsequently, the culture medium was aspirated and dimethyl sulfoxide $1000 \mu \mathrm{L} /$ well was added to dissolve the formazan completely for 10 minutes at $37^{\circ} \mathrm{C}$. Then $100 \mu \mathrm{L}$ of solution was transferred to a 96-well enzyme-linked immunosorbent assay plate and the absorbance was measured at $490 \mathrm{~nm}$ using a microplate reader (Multiskan MK3, Thermo Electron Corporation, Waltham, MA).

\section{Alkaline phosphatase activity}

MG-63 cells were seeded onto the samples and the alkaline phosphatase (ALP) activity of the cells was measured at different times. After 7 days, the culture medium in the 24-well plates was aspirated, and $200 \mu \mathrm{L}$ of $1 \%$ Nonidet $\mathrm{P}-40$ solution was added to each well at room temperature and incubated for one hour. The cell lysate was obtained and centrifuged, after which $50 \mu \mathrm{L}$ of supernatant was added to 96-well plates; $50 \mu \mathrm{L}$ of $2 \mathrm{mg} / \mathrm{mL}$ p-nitrophenyl phosphate (Sangon, Shanghai, China) substrate solution composed of $0.1 \mathrm{~mol} / \mathrm{L}$ glycine and $1 \mathrm{mmol} / \mathrm{L} \mathrm{MgCl}_{2} \cdot 6 \mathrm{H}_{2} \mathrm{O}$ was added and incubated for 30 minutes at $37^{\circ} \mathrm{C}$. The reaction was quenched by addition of $100 \mu \mathrm{L}$ of $0.1 \mathrm{~N} \mathrm{NaOH}$, and the ALP absorbance was quantified at the wavelength of $405 \mathrm{~nm}$ using a microplate reader (SPECTRAmax 384, Molecular Devices, Sunnyvale, CA). Total protein content in the cell lysate was determined using the bicinchoninic acid method in aliquots of the same samples using the Pierce protein assay kit (Pierce Biotechnology Inc, Rockford, IL), read at $560 \mathrm{~nm}$ and calculated according to a series of bovine serum albumin standards. ALP levels were normalized to the total protein content at the end of the experiment.

\section{Cell morphology}

The morphology of the MG-63 cells cultured on the composite samples was observed by scanning electron microscopy. At days 3 and 5, the samples were removed and washed with phosphate-buffered solution twice and fixed in $2.5 \%$ glutaraldehyde in $0.1 \mathrm{M}$ phosphate-buffered solution for 30 minutes. Thereafter, the fixed cells were washed with phosphate-buffered solution three times, and 
then dehydrated in ascending concentrations of ethanol (50, $60,70,80,90$, and $100 \%, v / v)$ for 5 minutes. The specimens were prepared by first immersing them in 50\% alcoholhexamethyldisilazane solution (v/v) for 10 minutes, and then in pure hexamethyldisilazane for 10 minutes. Later, the samples were vacuum-dried at $37^{\circ} \mathrm{C}$ overnight, and the morphology of the MG-63 cells in the samples was observed using a scanning electron microscope.

\section{Statistical analysis}

Statistical analysis was conducted using one-way analysis of variance with post hoc Tukey's tests. The results were expressed as the mean \pm standard deviation. A value of $P<0.05$ was considered to be statistically significant.

\section{Results and discussion Morphology of $n-C D H A$}

A transmission electron microscopic image of n-CDHA is shown in Figure 1. It can be seen that the n-CDHA crystals were needle-like with an approximate size of about 40-80 nm in length and $20-40 \mathrm{~nm}$ in diameter. The $\mathrm{Ca} / \mathrm{P}$ molar ratio of the n-CDHA was 1.52, as determined by inductively coupled plasma atomic emission spectroscopy. Therefore, the specimen prepared was calcium-deficient hydroxyapatite $\left[\mathrm{Ca}_{9.12}\left(\mathrm{HPO}_{4}\right)_{0.88}\left(\mathrm{PO}_{4}\right)_{5.12}(\mathrm{OH})_{1.12}, \mathrm{x}=0.88\right]$ according to the formula of nonstoichiometric hydroxyapatite:

$$
\left(\mathrm{Ca}_{10-\mathrm{X}}\left(\mathrm{HPO}_{4}\right)_{\mathrm{X}}\left(\mathrm{PO}_{4}\right)_{6-\mathrm{X}}(\mathrm{OH})_{2-\mathrm{X}}, 0 \leq \mathrm{x}<1\right) .
$$

Some studies have suggested that variation in the molar ratio of calcium to phosphate greatly affects the solubility of Ca-P biomaterials, and calcium phosphate with a $\mathrm{Ca} / \mathrm{P}$ of 1.50 degraded faster than hydroxyapatite with a $\mathrm{Ca} / \mathrm{P}$ of

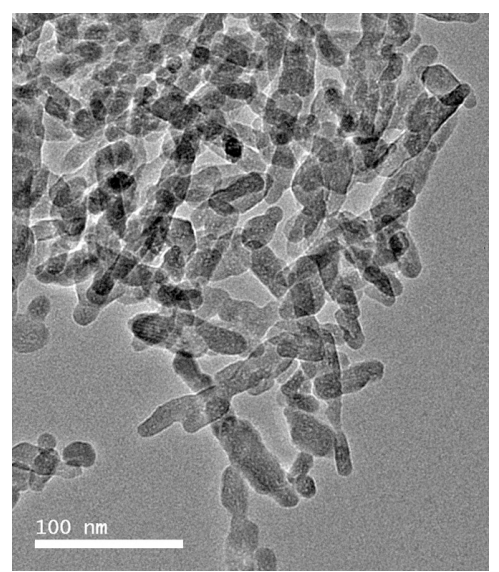

Figure I Transmission electron microscopic image of nano calcium-deficient hydroxyapatite.
1.67 when implanted in vivo..$^{7-9}$ Previous studies have shown that deficient calcium apatite, also called nonstoichiometric apatite, with a $\mathrm{Ca} / \mathrm{P}$ of 1.50 was biologically more active than hydroxyapatite with a $\mathrm{Ca} / \mathrm{P}$ of 1.67 because it has a composition and structure very close to that of natural bone mineral. ${ }^{9}$ Thus, it is envisaged that n-CDHA can be fabricated as a novel bone regeneration material in order to get better bioperformance of apatite biomaterial.

\section{Infrared analysis}

Figure 2A is the infrared spectrum of the multi(amino acid) copolymer. The peak at $3309 \mathrm{~cm}^{-1}$ is the nitrogen-hydrogen (NH) stretching vibration peak, and the bands around $2935 \mathrm{~cm}^{-1}$ and $2861 \mathrm{~cm}^{-1}$ are attributed to carbon hydrogen $\left(\mathrm{CH}_{2}\right)$ vibration peaks. The band at $1546 \mathrm{~cm}^{-1}$ represents the stretching vibration of carbon-nitrogen $(\mathrm{CN})$. The band at $1644 \mathrm{~cm}^{-1}$ is carbonyl vibration $(\mathrm{C}=\mathrm{O})$. These peaks indicate an amide copolymer structure. The Fourier transform infrared spectrum for n-CDHA is shown in Figure 2B. The peaks at $3572 \mathrm{~cm}^{-1}$ and $605 \mathrm{~cm}^{-1}$ represent the vibration of the hydroxyl $(\mathrm{OH})$ group, and the peaks at $561 \mathrm{~cm}^{-1}, 1030 \mathrm{~cm}^{-1}$, and $1101 \mathrm{~cm}^{-1}$ belong to $\mathrm{PO}_{4}^{3-}$. As shown in Figure $2 \mathrm{C}$, the peaks of hydroxyl of n-CDHA and those of the copolymer exist in the composite, indicating that the composite was composed of n-CDHA and multi(amino acid) copolymer. However, some peaks varied and moved to $3567 \mathrm{~cm}^{-1}(\mathrm{OH}), 3303 \mathrm{~cm}^{-1}(\mathrm{NH})$, $2936 \mathrm{~cm}^{-1}\left(\mathrm{CH}_{2}\right), 2862 \mathrm{~cm}^{-1}\left(\mathrm{CH}_{2}\right), 1544 \mathrm{~cm}^{-1}(\mathrm{CN})$, and $1640 \mathrm{~cm}^{-1}(\mathrm{C}=\mathrm{O})$. This might be because of amide-calciumamide linkage and the hydrogen bond formed between n-CDHA and the copolymer. ${ }^{18}$ The interaction at the interface between the polymer and inorganic mineral has been shown to have positive effects on the mechanical properties and distribution of inorganic particles in the composite. ${ }^{18,19}$

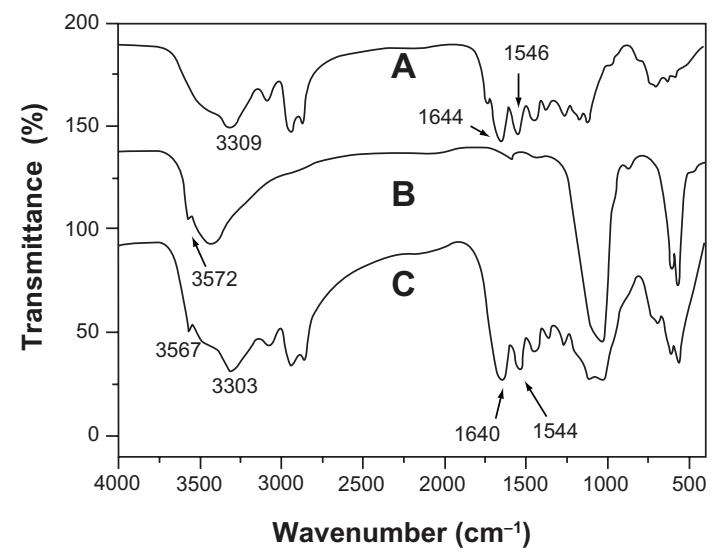

Figure 2 Infrared spectra of multi(amino acid) copolymer (A), nano calciumdeficient hydroxyapatite (B), and $30 \mathrm{wt} \%$ nano calcium-deficient hydroxyapatitemulti(amino acid) polymer composite (C). 


\section{X-ray diffraction analysis}

Figure 3 shows the $\mathrm{X}$-ray diffraction patterns for $\mathrm{n}-\mathrm{CDHA}$, multi(amino acid) copolymer, and the composite with $30 \mathrm{wt} \%$ n-CDHA. The peaks at $2 \theta=20^{\circ}$ and $23.8^{\circ}$ are attributed to the MAC (Figure 3A). The peaks at $2 \theta=25.7^{\circ}, 31.6^{\circ}$, $32.7^{\circ}, 33.8^{\circ}, 40^{\circ}, 47.1^{\circ}, 49.8^{\circ}$, and $53^{\circ}$ shown in Figure 3B indicate an apatite structure. All the aforementioned peaks were present in the composite, and no new peaks were found (Figure 3C). Hence, X-ray diffraction analysis results also show that the composite was composed of n-CDHA and the MAC. The peak intensities of MAC obviously decreased in the composite, as shown in Figure 3C. This change indicated that the presence of n-CDHA had significant effects on the crystallinity of the copolymer. This most likely resulted from the addition of $n$-CDHA to the composite, hindering the formation of hydrogen bonds in the molecular chain of the copolymer, and hence decreasing the regularity in the molecular chain.

\section{n-CDHA distribution in MAC}

The n-CDHA particle distribution in the composite shown in Figure 4 indicates that the n-CDHA particles were homogeneously dispersed in the MAC matrix, suggesting that the n-CDHA was still of a nanometer scale in the composite and that few agglomerations occurred during the synthesis process. Some n-CDHA particles were exposed on the composite surfaces, which was in favor of cell adhesion on the composite.

\section{Mechanical properties}

In general, the inorganic filler content in a polymer has obvious effects on the mechanical properties of an inorganic/ organic composite. In the present study, the effects of

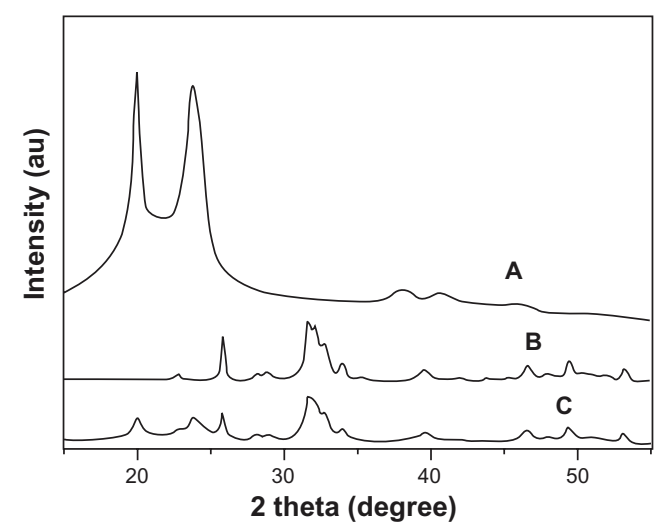

Figure 3 X-ray diffraction patterns of multi(amino acid) copolymer $(\mathbf{A})$, nano calcium-deficient hydroxyapatite (B), and $30 \mathrm{wt} \%$ nano calcium-deficient hydroxyapatite-multi(amino acid) copolymer composite (C).

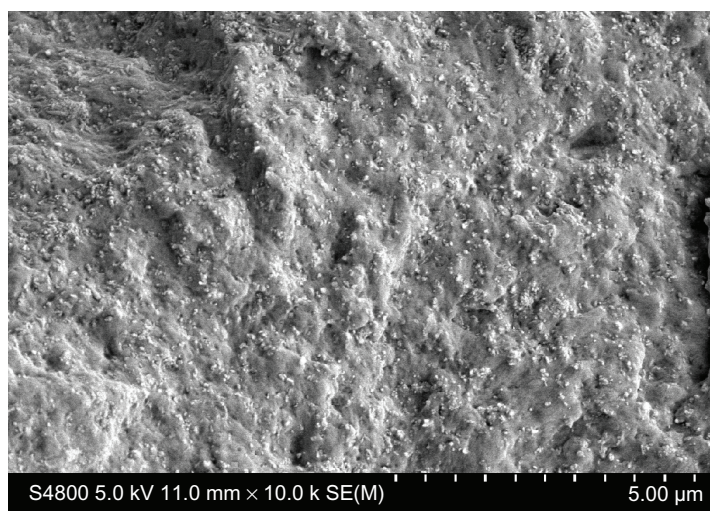

Figure 4 Cross-sectional morphology of 30 wt\% nano calcium-deficient hydroxyapatite-multi(amino acid) copolymer composite.

varying amounts of $n-C D H A$ on the compressive strength of the composite are shown in Figure 5. It was found that the compressive strength of the n-CDHA-MAC composites ranged from $88 \mathrm{MPa}$ to $129 \mathrm{MPa}$, which is close to that of natural cortical bone tissue (around 50-140 MPa), ${ }^{20}$ and increased with increasing amounts of n-CDHA in the composite (from $10 \mathrm{wt} \%$ to $40 \mathrm{wt} \%$ ). No significant difference in compressive strength was found between the MAC and the 10CDHA-MAC $(P>0.05)$ and 30CDHA-MAC and 40CDHA-MAC composites $(P>0.05)$. However, when the content of apatite in the polymer was $50 \mathrm{wt} \%$, the compressive strength of the composite decreased significantly as compared with the 40CDHA-MAC composite $(P<0.05)$, and the samples were collapsed, exhibiting brittleness. The results indicate that the n-CDHA-MAC composite with $30 \mathrm{wt} \%$ or $40 \mathrm{wt} \%$ amounts of apatite in the polymer had higher mechanical strength.

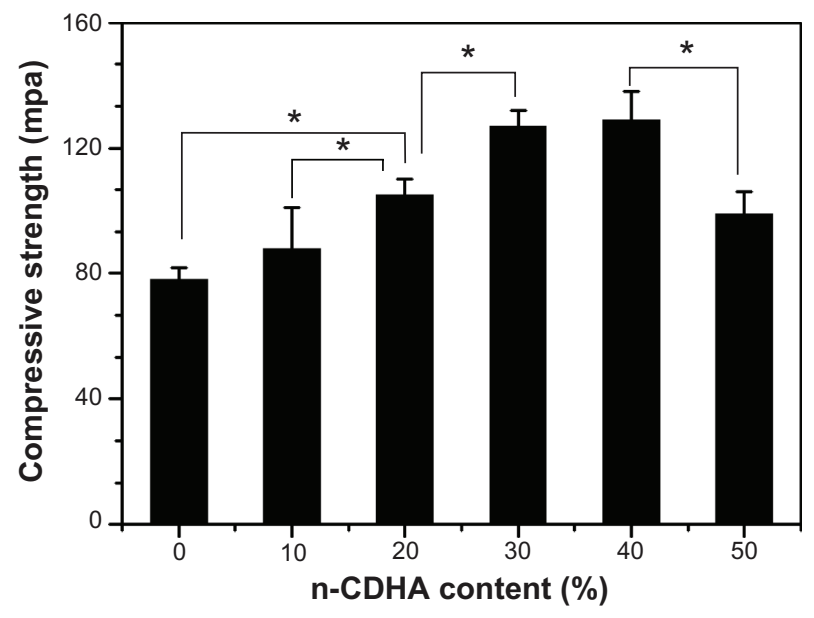

Figure 5 Effects of nano calcium-deficient hydroxyapatite (n-CDHA) contents on the compressive strength of nano calcium-deficient hydroxyapatite-multi(amino acid) copolymer composite.

Note: $* p<0.05$. 


\section{Degradation in phosphate-buffered solution}

Figure 6 shows the degradability of the n-CDHA-MAC composite soaked in phosphate-buffered solution over time. It was found that weight loss from both MAC and the composite increased in phosphate-buffered solution with time, indicating that the samples were degradable. In addition, weight loss from the composite increased according to the n-CDHA content in the polymer. When the n-CDHA content was $20 \mathrm{wt} \%$, weight loss from the composite was significantly higher than from the MAC $(P<0.05)$. No significant difference was found in the extent of weight loss between the MAC and 10CDHA-MAC. After 12 weeks of immersion, weight loss from the 30CDHA-MAC and 40CDHA-MAC composites reached $41.5 \mathrm{wt} \%$ and $44.3 \mathrm{wt} \%$. However, the 40CDHA-MAC samples were degraded after soaking for 8 weeks.

Generally, the dissolution behavior of n-CDHA is mainly dependent on the molar ratio of $\mathrm{Ca} / \mathrm{P}$. n-CDHA with a lower ratio shows better solubility. In our study, the $\mathrm{Ca} / \mathrm{P}$ molar ratio of n-CDHA was 1.52 , indicating that it had good solubility. In addition, the nanoparticles were uniformly distributed in the polymer matrix. When the composite was incubated in soaking medium, the polymer first degraded and then the nanoparticles could be dissolved. Obviously, dissolution of the composite was faster than degradation of the polymer, and weight loss from the n-CDHA-MAC composite reflected degradation of both the n-CDHA and MAC.

However, addition of nanoparticles to a degradable polymer can also alter the degradation behavior by, eg, increasing hydrophilicity and decreasing crystallinity. ${ }^{21}$ For

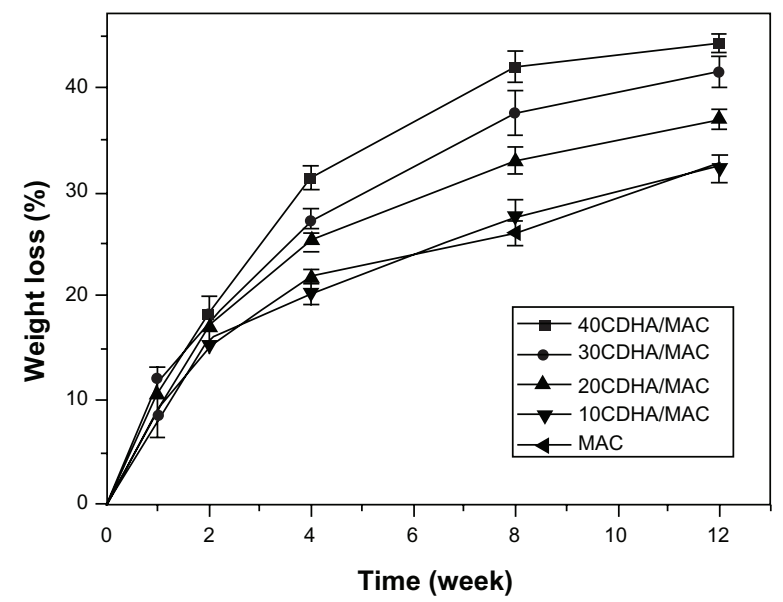

Figure 6 Weight loss of the nano calcium-deficient hydroxyapatite-multi(amino acid) copolymer (CDHA/MAC) composite after soaking in phosphate-buffered solution with time.

Abbreviation: MAC, multi(amino acid) copolymer. the n-CDHA-MAC composite, when the nanoparticles were dissolved in the soaking medium and micropores were formed, the erosion surface of the MAC increased, indicating a higher degradation rate than that of pure MAC. Moreover, our X-ray diffraction results show that addition of $\mathrm{n}-\mathrm{CDHA}$ decreased the crystallinity of MAC compared with the pure specimen, which also had an increased degradation rate because the amorphous region of a semicrystalline polymer undergoes faster degradation, as a result of a higher rate of water uptake in the free volume than in the crystalline regions. ${ }^{22}$

Generally, implants which are degradable in vivo with an appropriate degradation rate allow host tissue growth until healing is complete, while eliminating the need for a second operation to remove the implant. ${ }^{11,23}$ In this study, the n-CDHA-MAC composites with $30 \mathrm{wt} \%$ and $40 \mathrm{wt} \%$ exhibited suitable degradation in phosphate-buffered solution over time, and the mechanical strength of the $30 \mathrm{wt} \%$ n-CDHA composite was higher than that of the $40 \mathrm{wt} \%$ specimen after soaking for 12 weeks. Therefore, it could be suggested that the composite with $30 \mathrm{wt} \% \mathrm{n}$-CDHA has the potential to provide enough mechanical strength to meet the fundamental requirements of a bone substitute.

\section{$\mathrm{pH}$ change of the soaking solution}

The changes in $\mathrm{pH}$ of the phosphate-buffered solution after soaking the n-CDHA-MAC composite and MAC for different time periods are shown in Figure 7. $\mathrm{pH}$ increased slightly with increasing amounts of n-CDHA in the n-CDHA-MAC composites during soaking of the samples over 12 weeks. In the case of the MAC, the $\mathrm{pH}$ gradually increased from 6.9 to 7.1 over 12 weeks of soaking, whereas the $\mathrm{pH}$ gradually

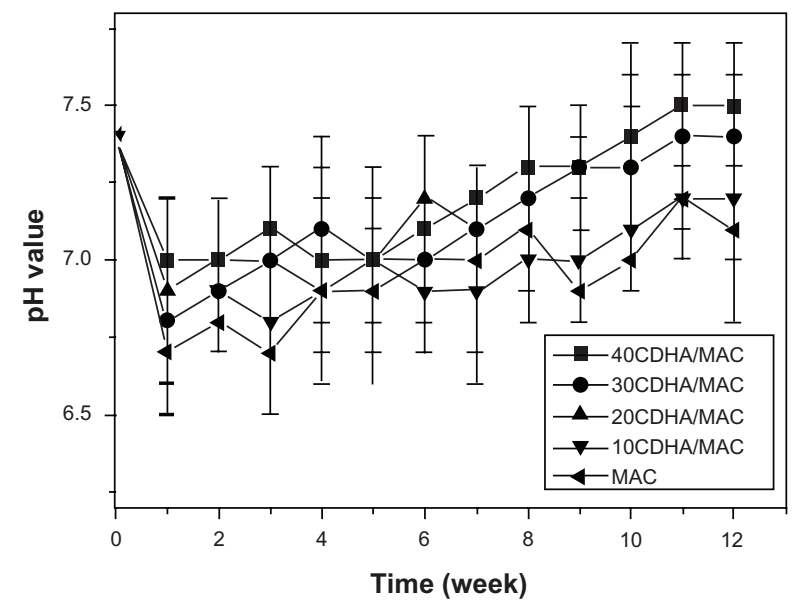

Figure $7 \mathrm{pH}$ change of the phosphate-buffered solution after nano calciumdeficient hydroxyapatite-multi(amino acid) copolymer (CDHA/MAC) composite soaking with time.

Abbreviation: MAC, multi(amino acid) copolymer. 
rose from 6.9 and stabilized at 7.3 for the CDHA-MAC composites. During incubation in the phosphate-buffered solution, the amide bonds were cleaved for hydrolysis and degraded into oligomers and eventually into monomers. These amino acid monomers, with the exception of lysine, show weak acidity in liquid solution because there is more $\mathrm{H}^{+}$formed by the carboxyl groups than those bound by the amino groups, resulting in a $\mathrm{pH}$ decrease in the soaking medium. Therefore, the higher the degradation rate, the lower the $\mathrm{pH}$ value. When the degradation rate decreased, $\mathrm{pH}$ gradually increased. In addition, the $\mathrm{pH}$ of the composite was higher than that of the MAC. This may be attributed to the weakly alkaline nature of n-CDHA.

The $\mathrm{pH}$ of the physiological environment after biomaterials are implanted in vivo would greatly influence the interactions between cells and implants via cellular responses. Some researchers have shown that an acidic (low $\mathrm{pH}$ ) environment might be clinically undesirable for cell survival. ${ }^{24}$ For degradable polymeric materials like polylactic acid, the acidic byproducts of degradation result in a decrease in the $\mathrm{pH}$ of the ambient environment, and hence induce an inflammatory reaction after implantation in vivo. ${ }^{25}$ In this study, the $\mathrm{pH}$ of the soaking solutions varied from 6.9 to 7.5 , indicating that degradation byproducts of the n-CDHA-MAC composite had little effect on the $\mathrm{pH}$ of the phosphate-buffered solution, and therefore were unlikely to have adverse effects on cells in vivo.

\section{Cytocompatibility}

\section{Cell adhesion}

After 4 hours of culture, cell adhesion on the n-CDHA-MAC composite was investigated using MG-63 cells, MAC, and a tissue culture plate as the control. Over 4 hours, the cell adhesion rate on the composite was $117 \%$, on the MAC was $108 \%$, and for the tissue culture plate was $100 \%$. The results show that the cell adhesion rate for the n-CDHA-MAC composite was higher than for the control, indicating that incorporation of n-CDHA into MAC facilitated cell adhesion on the composite.

Adhesion is part of the first phase of cell-material interaction, and the quality of this first phase will influence the cell's capacity for growth, morphology, proliferation, and differentiation upon contact with the implant. ${ }^{26}$ The cell adhesion results of this study indicate that MG-63 osteoblast-like cells adhered better to the n-CDHA-MAC composite with $30 \mathrm{wt} \% \mathrm{n}-\mathrm{CDHA}$ than to the MAC and to the tissue culture plate control within the first 4 hours. The superior ability of MG-63 cells to attach to the composite

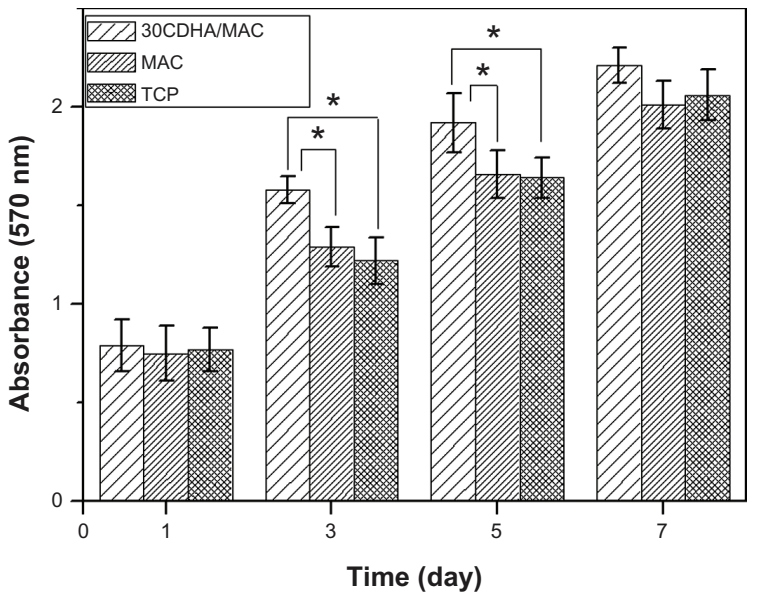

Figure 8 Viability of MG-63 cells on 30 wt\% nano calcium-deficient hydroxyapatitemulti(amino acid) copolymer (30CDHA/MAC) composite by MTT assay at I, 3, 5 and 7 days (MAC and tissue culture plate as controls).

Note: $* P<0.05$.

Abbreviations: MAC, multi(amino acid) copolymer; TCP, tissue culture plate.

probably reflects the differing material surface features of the composite and the MAC. The nanosized calcium-deficient hydroxyapatite in the MAC expose the composite surfaces that had additional surface properties, which improved cell adhesion. ${ }^{26,27}$

\section{Cell viability}

The MTT assay was used to evaluate MG-63 cell viability on the 30CDHA-MAC composite because optical density values can provide an indicator of cell viability on biomaterials. It can be seen in Figure 8 that the optical density of the composite and the controls (MAC and tissue culture plate) increased significantly with time, suggesting that MG-63 cells were

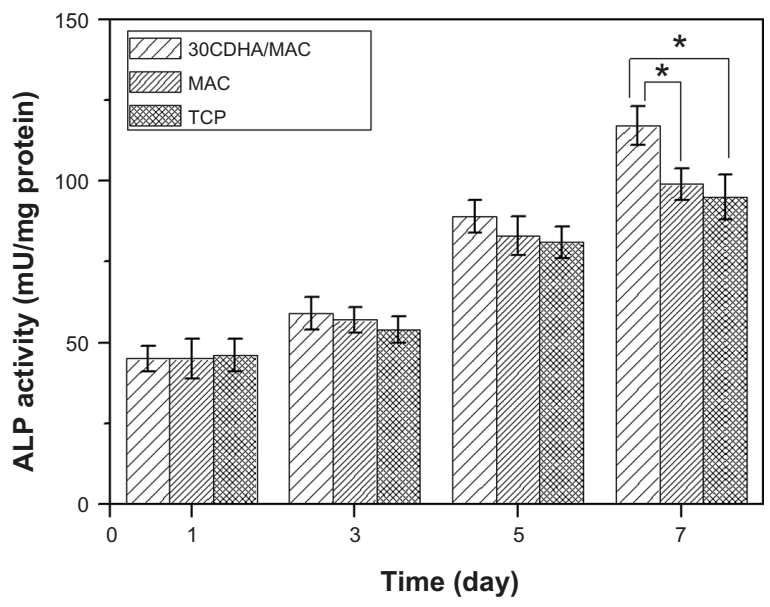

Figure 9 ALP activity of MG-63 cells cultured on $30 \mathrm{wt} \%$ nano calcium-deficient hydroxyapatite-multi(amino acid) copolymer (30CDHA/MAC) composite, multi(amino acid) copolymer (MAC), and tissue culture plate (TCP) as controls.

Note: $* P<0.05$.

Abbreviation: ALP, alkaline phosphatase. 

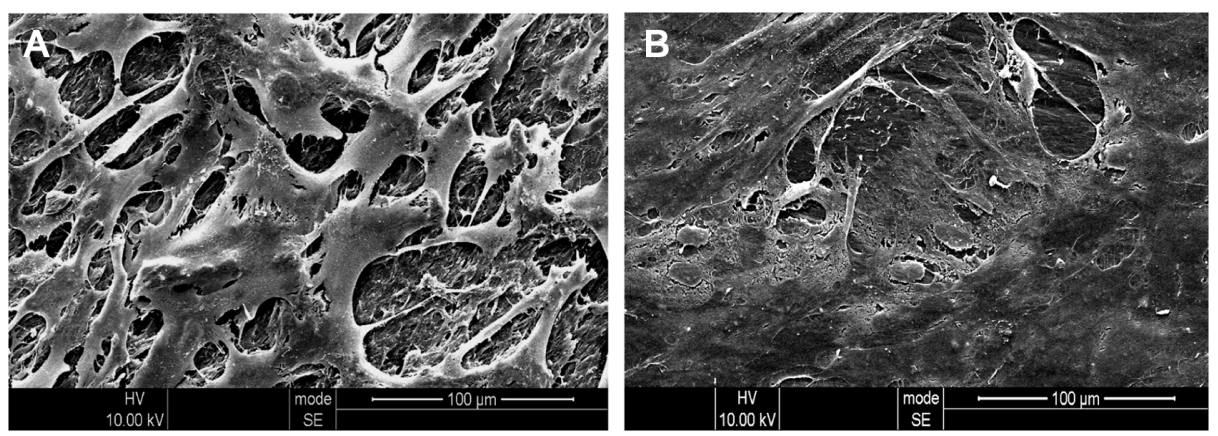

Figure I 0 Scanning electron microscopic images of MG-63 cells cultured on multi(amino acid) copolymer (A) and 30 wt\% nano calcium-deficient hydroxyapatite-multi(amino acid) copolymer composite (B) for 3 days.

viable on these samples, showing positive cellular responses to the composite and controls, with the composite having good cytocompatibility, similar to that of the controls.

There was no significant difference in optical density between the composite and controls at days 1 and 7. However, the optical density of the CDHA-MAC composite was higher than for the MAC and tissue culture plate at 3 and 5 days $(P<0.05)$, indicating that the composite could improve cell viability and that the biological properties of the composite were superior to those of the MAC. Ideally, bioactive biomaterials need to interact actively with cells and stimulate cell growth. In this study, the optical density of the n-CDHA composite was significantly higher than that of the MAC at 3 and 5 days, indicating that the composite could enhance MG-63 osteoblast-like cell growth. Therefore, it could be suggested that the n-CDHA in the composite might be responsible for stimulating cell growth. ${ }^{26,28}$

\section{ALP activity}

The ALP activity of MG-63 cells cultured on the 30CDHAMAC composite and the controls (MAC and tissue culture plate) was determined at days $1,3,5$, and 7 , and the results are shown in Figure 9. The ALP activity of MG-63 cells cultured on the composite and controls increased over time, with no significant difference found at days 1, 3, and 5. However, ALP activity in the cells on the composite was significantly higher than that of controls at 7 days $(P<0.05)$.

ALP is an enzyme secreted by osteoblasts and is a marker of osteoblastic phenotype and mineralization..$^{29}$ In this study, the composite containing $30 \mathrm{wt} \% \mathrm{n}$-CDHA showed significantly higher levels of ALP expression than did the MAC and tissue culture plate at 7 days, indicating that the cells differentiated more quickly after being cultured on the composite than on the control. Therefore, the biggest advantage of the composite containing n-CDHA appears to be its superior ALP activity as compared with the MAC. This increased activity probably resulted from the n-CDHA in the composite, which might be responsible for stimulating cell differentiation. ${ }^{26,29-31}$

\section{Cell morphology}

Scanning electron microscopic images of MG-63 cells cultured on the 30CDHA-MAC composite and the MAC for 3 days are shown in Figure 10. At 3 days, the cells were well spread on both the composite and the MAC surfaces, and had a sheet shape because of inoculation after its viability. In addition, the cells extended out and formed a confluent layer with close attachment to both the composite and MAC surfaces, with more cells present on the composite than on the MAC surface. These results are consistent with those of previous studies, showing that the addition of calcium phosphate particles to a polymer improves the biological properties of composites and has positive effects on cell morphology and viability. ${ }^{29,32}$

\section{Conclusion}

The amount of n-CDHA in the copolymer had obvious effects on the compressive strength of the copolymer, and a composite containing $30 \mathrm{wt} \% \mathrm{n}$-CDHA showed good mechanical performance. Weight loss from the composite into phosphate-buffered solution increased with the n-CDHA content in the polymer, and the degradation byproducts of the composite had no significant effect on the $\mathrm{pH}$ of the soaking solution. The results demonstrate that introduction of $\mathrm{n}-\mathrm{CDHA}$ into the MAC gave rise to a bioactive and more degradable n-CDHA-MAC composite, and that the n-CDHA in the composite improved adhesion, viability, and differentiation of MG-63 osteoblast-like cells. It can be suggested that incorporation of n-CDHA into MAC could enhance the biological properties of the composite. This composite had good cytocompatibility and could be used as a bioactive bone implant that might stimulate tissue regeneration. 


\section{Acknowledgments}

The authors are grateful for the financial support of the National Natural Science Foundation of China (31070834), the Key Medical Program of Science and Technology Development of Shanghai (09411954900), and the Nano special program of Science and Technology Development of Shanghai (1052nm06600).

\section{Disclosure}

The authors report no conflicts of interest in this work.

\section{References}

1. Shokrollahi P, Mirzadeh H, Scherman OA, et al. Biological and mechanical properties of novel composites based on supramolecular polycaprolactone and functionalized hydroxyapatite. $J$ Biomed Mater Res A. 2010;95A(1):209-221.

2. Dai CL, Liu CS, Wei J, et al. Molecular imprinted macroporous chitosan coated mesoporous silica xerogels for hemorrhage control. Biomaterials. 2010;31(30):7620-7630.

3. Wang HN, Li YB, Zuo Y, et al. Biocompatibility and osteogenesis of biomimetic nano-hydroxyapatite/polyamide composite scaffolds for bone tissue engineering. Biomaterials. 2007;28(22):3338-3348.

4. Chang BS, Lee CK, Hong KS, et al. Osteoconduction at porous hydroxyapatite with various pore configurations. Biomaterials. 2000;21(12):1291-1299.

5. Hanifi A, Hossein FM. Bioresorbability evaluation of hydroxyapatite nanopowders in a stimulated body fluid medium. Iranian Journal of Pharmaceutical Sciences. 2008;4(2):141-148.

6. LeGeros RZ, Lin S, Rohanizadeh R, et al. Biphasic calcium phosphate bioceramics: preparation, properties and applications. J Mater Sci Mater Med. 2003;14(3):201-209.

7. Siddharthan A, Seshadri SK, Sampath Kumar TS. Rapid synthesis of calcium deficient hydroxyapatite nanoparticles by microwave irradiation. Trends Biomater Artif Organs. 2005;18(2):110-113

8. Guo H, Su JC, Wei J, et al. Biocompatibility and osteogenicity of degradable Ca-deficient hydroxyapatite scaffolds from calcium phosphate cement for bone tissue engineering. Acta Biomater. 2009;5(1):268-278.

9. Lin JHC, Kuo KH, Ding SJ, et al. Surface reaction of stoichiometric and calcium-deficient hydroxyapatite in simulated body fluid. $J$ Mater Sci Mater Med. 2001;12(8):731-741.

10. Greish YE. Phase evolution during the low temperature formation of calcium-deficient hydroxyapatite-gypsum composites. Ceramics International. 2011;37(5):1493-1500.

11. Sun H, Meng F, Dias AA, et al. $\alpha$-amino acid containing degradable polymers as functional biomaterials: rational design, synthetic pathway, and biomedical applications. Biomacromolecules. 2011;12(6):1937-1955.

12. Hofmann D, Entrialgo M, Reiche J, et al. Molecular modeling and experimental investigation of hydrolytically degradable polymeric biomaterials. Advances in Science and Technology. 2010;76:16-24.

13. McBane JE, Sharifpoor S, Cai KH, et al. Biodegradation and in vivo biocompatibility of a degradable, polar/hydrophobic/ionic polyurethane for tissue engineering applications. Biomaterials. 2011;32(26):6034-6044.

International Journal of Nanomedicine

\section{Publish your work in this journal}

The International Journal of Nanomedicine is an international, peerreviewed journal focusing on the application of nanotechnology in diagnostics, therapeutics, and drug delivery systems throughout the biomedical field. This journal is indexed on PubMed Central, MedLine, CAS, SciSearch ${ }^{\circledR}$, Current Contents ${ }^{\circledR} /$ Clinical Medicine,
14. Zhang WP, Shao JM. Biomedical research of novel biodegradable copoly(amino acid)s based on 6-aminocaproic acid and L-proline. J Biomed Mater Res A. 2009;94(2):450-456.

15. Zhang W, Huang YQ. Biodegradable copoly(amino acid)s based on 6aminocaproic acid and L-leucine. J Polym Environ. 2010;19(1):177-181.

16. Li H, Yan YG, Wei J, et al. Bone substitute biomedical material of multi(amino acid) copolymer: in vitro degradation and biocompatibility. J Mater Sci Mater Med. 2011;22(11):2555-2563.

17. Bianco A, Di Federico E, Moscatelli I, et al. Electrospun poly ( $\varepsilon$-caprolactone)/Ca-deficient hydroxyapatite nanohybrids: microstructure, mechanical properties and cell response by murine embryonic stem cells. Mater Sci Eng C Mater Biol Appl. 2009;29(6):2063-2071.

18. Wei J, LiYB. Tissue engineering scaffold material of nano-apatite crystals and polyamide composite. Eur Polym J. 2004;40(3):509-515.

19. Wei J, Heo SJ, Kim DH, et al. Comparison of physical, chemical and cellular responses to nano and micro-sized calcium silicate poly epsilon caprolactone bioactive composites. J R Soc Interface. 2008;5(23): 617-630.

20. Verheyen CC, de Wijn JR, van Blitterswijk CA, et al. Evaluation of hydroxyapatite/poly(L-lactide)composites mechanical behavior. J Biomed Mater Res. 1992;26(10):1277-1296.

21. Armentano I, Dottori M, Fortunati E, et al. Biodegradable polymer matrix nanocomposites for tissue engineering: A review. Polym Degrad Stab. 2010;95(11):2126-2146.

22. Middleton JC, Tipton AJ. Synthetic biodegradable polymers as orthopedic devices. Biomaterials. 2000;21(23):2335-2346.

23. Hofmann D, Entrialgo-Castaño M, Kratz K, et al. Knowledge-based approach towards hydrolytic degradation of polymer-based biomaterials. Adv Mater. 2009;21(32-33):3237-3245.

24. Richert L, Arntz Y, Schaaf P, et al. pH dependent growth of poly (L-lysine)/poly(L-glutamic) acid multilayer films and their cell adhesion properties. Surf Sci. 2004;570(1-2):13-29.

25. Yuan XY, Mak AFT, Yao KD. In vitro degradation of poly(L-lactic acid) fibers in phosphate buffered saline. J Appl Polym Sci. 2002;85(5): 936-943.

26. Dulgar-Tulloch AJ, Bizios R, Siegel RW. Human mesenchymal stem cell adhesion and proliferation in response to ceramic chemistry and nanoscale topography. J Biomed Mater Res A. 2009;90(2):586-594.

27. Ribeiro N, Sousa SR, Monteiro FJ. Influence of crystallite size of nanophased hydroxyapatite on fibronectin and osteonectin adsorption and on MC3T3-E1 osteoblast adhesion and morphology. J Colloid Interface Sci. 2010;351(2):398-406.

28. LeGeros RZ. Calcium phosphate-based osteoinductive materials. Chem Rev. 2008;108(11):4742-4753.

29. Lao LH, Wang YJ, Zhu Y, et al. Poly(lactide-co-glycolide)/hydroxyapatite nanofibrous scaffolds fabricated by electrospinning for bone tissue engineering. J Mater Sci Mater Med. 2010;22(8):4374-4378.

30. Gupta D, Venugopal J, Mitra S, et al. Nanostructured biocomposite substrates by electrospinning and electrospraying for the mineralization of osteoblasts. Biomaterials. 2009;30(11):2085-2094.

31. Ngiam M, Liao SS, Patil AJ, et al. The fabrication of nano-hydroxyapatite on PLGA and PLGA/collagen nanofibrous composite scaffolds and their effects in osteoblastic behavior for bone tissue engineering. Bone. 2009;45(1):4-16.

32. Cui Y, Liu Y, Cui Y, et al. The nanocomposite scaffold of poly(lactideco-glycolide) and hydroxyapatite surface-grafted with L-lactic acid oligomer for bone repair. Acta Biomaterialia. 2009;5(7):2680-2692.

\section{Dovepress}

Journal Citation Reports/Science Edition, EMBase, Scopus and the Elsevier Bibliographic databases. The manuscript management system is completely online and includes a very quick and fair peer-review system, which is all easy to use. Visit http://www.dovepress.com/ testimonials.php to read real quotes from published authors. 